\title{
Health-related quality of life in patients with anal fissure: effect of type D personality
}

\author{
Mustafa Sit ${ }^{1}$, Edip Erdal Yilmaz ${ }^{1}$, Fatih Canan², Osman Yildirim³, Mehmet Mustafa Cetin ${ }^{4}$ \\ ${ }^{1}$ Department of General Surgery, Abant Izzet Baysal University, School of Medicine, Bolu, Turkey \\ ${ }^{2}$ Psychiatry Clinic, Bolu Izzet Baysal Mental Health Hospital, Bolu, Turkey \\ ${ }^{3}$ Department of Psychiatry, Abant Izzet Baysal University, School of Medicine, Bolu, Turkey \\ ${ }^{4}$ General Surgery Clinic, Agri State Hospital, Agri, Turkey
}

Prz Gastroenterol 2014; 9 (2): 93-98

DOI: $10.5114 / p g .2014 .42504$

Key words: anal fissure, negative affect, quality of life, social inhibition, type D personality.

Address for correspondence: Mustafa Sit MD, Department of General Surgery, Abant Izzet Baysal University, School of Medicine, 14280, Golkoy, Bolu, Turkey, phone: +90 37425345 68, fax: +90 37425345 59, e-mail: drmustafasit@yahoo.com.tr

\begin{abstract}
Introduction: Health-related quality of life (HRQL) is a significant factor in describing the burden of illness and the impact of treatment in patients with gastrointestinal disease. Type $D$ (distressed) personality is defined as the co-occurrence of negative affect and social inhibition.

Aim: To assess the prevalence of type D personality in patients with anal fissure and to investigate whether the presence of a type $D$ personality would affect HRQL in patients with anal fissure.

Material and methods: One hundred outpatients with anal fissure with no psychiatric comorbidity were consecutively enrolled, along with 100 healthy controls. Type D Scale (DS14) and General Health Survey Short Form-36 (SF-36) were used in the collection of data.

Results: Patients with anal fissure scored lower on physical roles and bodily pain dimensions of SF-36 than healthy subjects $(p<0.05)$. Thirty-three patients with anal fissure $(33 \%)$ and 16 controls $(16 \%)$ had scored above the cut-off score of the DS14 $(p<0.05)$. Patients with a type $D$ personality were found to score lower on bodily pain and social roles domains of HRQL than patients without a type D personality.

Conclusions: Type D personality was associated with increased perceived bodily pain and social roles in patients with anal fissure. Type D personality construct may be an important consideration when assessing HRQL outcomes. A multidimensional approach may be valuable in the assessment of patients presenting with anal fissure, because a subgroup with type-D personality might benefit from psychological therapies.
\end{abstract}

\section{Introduction}

An anal fissure is a cut or split in the epithelial lining of the anal canal distal to the dentate line. They are the most common causes of severe anorectal pain. A chronic anal fissure is usually categorised when the fissure fails to heal within 6 to 8 weeks. Chronic fissures develop ulceration and heaped-up edges with exposure of the internal anal sphincter fibre at the base of the ulcer. Characteristic symptoms include tearing pain with defecation and haematochezia that is usually present as blood on toilet paper. It has been estimated that anal fissure afflicts about $10 \%$ of patients attending colorectal clinics, with both sexes affected equally [1].
The type $D$ (distressed) personality is defined as the stable inclination to experience both negative affectivity (NA) and social inhibition (SI) [2]. Negative affectivity refers to a tendency to experience negative emotions such as hostility, depression and anger at various times and in various situations. Social inhibition connotes the tendency to hold back the expression of these emotions in social interaction due to fears of rejection or disapproval by others [2]. Type D patients are reported to experience decreased levels of social support and to be less likely to engage in positive health related behaviour [3]. They also fail to consult for increased symptom levels, although they experience more symptoms than non-type $D$ patients [4]. Type D personality has been 
receiving a lot of attention as an important indicator of adverse clinical outcome not only in cardiac patients [5], but also in patients without cardiovascular disease [6].

Health-related quality of life (HRQL) is an important patient-centred outcome that is receiving increasing attention. It is a multi-dimensional aspect of health and illness that incorporates a range of variables related to health, such as physical health and functioning, emotional functioning, role limitations and social functioning. Health-related quality of life is a significant factor in describing the burden of illness and the impact of treatment in patients with gastrointestinal disease [7].

\section{Aim}

To our knowledge, the HRQL of patients with anal fissure has been evaluated only in a few studies [8-10]. Moreover, the inter-relationship between personality traits and anal fissure has not been investigated until now. The first objective of the present study was to assess the prevalence of type $D$ personality in patients with anal fissure, in comparison with healthy volunteers. Our second objective was to investigate whether the presence of a type $D$ personality would affect sense of well-being (HRQL).

\section{Material and methods \\ Study subjects}

One hundred consecutive outpatients suffering from anal fissure, who were treated at the Department of General Surgery of a University Hospital in the northwest region of Turkey between May 2012 and July 2012, were included in this study. The medical history of all the patients was carefully studied, and all patients underwent inspection and digital exploration. Chronic anal fissure was diagnosed when symptoms had been present for more than 6 weeks and there were signs of chronicity on examination (induration, sentinel pile and/or visible sphincter fibres at the base). Patients were additionally screened to rule out organic bowel diseases, other chronic pains and psychiatric conditions (including fibromyalgia and chronic fatigue syndrome). Additional exclusion criteria required that the patients had not undergone any major surgery in the past 2 years and did not have a history of diabetes. One hundred healthy controls were also included in the study in order to compare the HRQL and type D personality among groups. All controls were screened for similar exclusion factors, including any history of chronic pain, psychiatric illness, major surgery and medication. Healthy controls were selected from the community or staff members of the institute, excluding those fulfilling for anal fissure on enquiry.
The study protocol was approved by the Institutional Ethics Committee. Informed consent was obtained from all the patients and controls.

\section{Questionnaires}

Type D Scale (DS14)

Type D personality was assessed with the DS14 questionnaire [2]. The DS14 is a 14-item questionnaire that measures two stable personality traits: NA and SI. Subjects rate these aspects of their personality on a 5 -point Likert scale as follows: $0=$ false, $1=$ rather false, 2 = neutral, 3 = rather true and $4=$ true. The NA and SI scales are then scored as continuous variables (range: 0-28). A cutoff of 10 on both scales was used to classify subjects as type $D(N A \geq 10$ and $S I \geq 10)$. The DS14 is an internally consistent (Cronbach's $\alpha$ : NA/SI $=0.88 / 0.86)$ and stable (3-month test-retest reliability: $\mathrm{NA} / \mathrm{SI}=0.72 / 0.82)$ measure. For the Turkish version [11], the Cronbach's $\alpha$ coefficients of the NA and SI subscales were 0.82 and 0.81 , respectively.

\section{General Health Survey Short Form-36}

\section{(SF-36)}

Health-related quality of life was measured by SF-36, which is one of the best-known scales used to measure HRQL, a subjective concept that is constituted at perception level [12]. The SF-36 consists of 36 questions evaluating the respondent's perception of their performance in terms of 8 dimensions of daily life: physical functioning, role physical, bodily pain, general health, vitality, social functioning, role emotional and mental health dimensions. Responses from the SF-36 are summed and then transformed to give 8 scores with a 0-100 scale, where higher scores indicate better function in that dimension. The SF-36 has been tested and proven to be a reliable, valid and sensitive measure of health status in the general population in various countries, including Turkey [13].

\section{Statistical analysis}

Statistical Package for Social Sciences software (SPSS 16, Chicago, IL, USA) was used for analysis. Descriptive parameters were shown as mean \pm standard deviation or as percentages. Variables were checked for normal distribution, and normally distributed variables were compared using the Student $t$ test. Abnormally distributed variables were compared using the Mann-Whitney $U$ test. Pearson's $\chi^{2}$ test was used to analyse the differences in means and proportions between groups. Spearman's or Pearson correlation tests were used to evaluate the association between negative affectivity and social inhibition and age, duration 
Table I. Characteristics of the total sample, stratified by anal fissure status

\begin{tabular}{|c|c|c|c|c|c|c|}
\hline \multicolumn{2}{|c|}{ Parameter } & \multicolumn{2}{|c|}{ Control $(n=100)$} & \multicolumn{2}{|c|}{ Anal fissure $(n=100)$} & \multirow[t]{2}{*}{ Value of $p$} \\
\hline & & Mean & SD & Mean & SD & \\
\hline Age $^{*}$ & & 34.2 & 13.2 & 34.1 & 11.5 & 0.721 \\
\hline Negative affectivity* & & 8.5 & 2.3 & 9.6 & 3.9 & 0.020 \\
\hline Social inhibition* & & 8.7 & 3.3 & 9.1 & 3.9 & 0.852 \\
\hline Physical function* & & 79.1 & 17.1 & 77.5 & 18.4 & 0.115 \\
\hline Physical roles* & & 81.4 & 13.9 & 77.3 & 16.1 & 0.044 \\
\hline Bodily pain* & & 83.6 & 20.5 & 73.8 & 20.6 & $<0.001$ \\
\hline General health $^{\dagger}$ & & 79.4 & 13.6 & 76.2 & 13.8 & 0.181 \\
\hline Vitality $^{\dagger}$ & & 82.8 & 10.5 & 79.7 & 14.3 & 0.176 \\
\hline Social roles ${ }^{\dagger}$ & & 84.4 & 10.1 & 79.7 & 16.9 & 0.076 \\
\hline Emotional roles $^{\dagger}$ & & 83.4 & 11.5 & 79.3 & 16.5 & 0.084 \\
\hline Mental health $^{\dagger}$ & & 85.6 & 10.7 & 83.9 & 10.1 & 0.361 \\
\hline \multirow[t]{2}{*}{ Gender, $n(\%)^{\ddagger}$} & Male & \multicolumn{2}{|c|}{$54(54)$} & \multicolumn{2}{|c|}{$52(52)$} & 0.477 \\
\hline & Female & \multicolumn{2}{|c|}{$46(46)$} & \multicolumn{2}{|c|}{$48(48)$} & \\
\hline \multirow[t]{3}{*}{ Marital status, $n(\%)^{\ddagger}$} & Single & \multicolumn{2}{|c|}{$26(26)$} & \multicolumn{2}{|c|}{$20(20)$} & 0.375 \\
\hline & Married & \multicolumn{2}{|c|}{$72(72)$} & \multicolumn{2}{|c|}{79 (79) } & \\
\hline & Widowed & \multicolumn{2}{|c|}{$2(2)$} & \multicolumn{2}{|c|}{$1(1)$} & \\
\hline \multirow[t]{5}{*}{ Education, $n(\%)^{\ddagger}$ [years] } & $2-4$ & \multicolumn{2}{|c|}{$30(30)$} & \multicolumn{2}{|c|}{$33(33)$} & 0.835 \\
\hline & 5 & \multicolumn{2}{|c|}{$32(32)$} & \multicolumn{2}{|c|}{$30(30)$} & \\
\hline & 8 & \multicolumn{2}{|c|}{$14(14)$} & \multicolumn{2}{|c|}{$13(13)$} & \\
\hline & 12 & \multicolumn{2}{|c|}{$18(18)$} & \multicolumn{2}{|c|}{$21(21)$} & \\
\hline & $>12$ & \multicolumn{2}{|c|}{$3(3)$} & \multicolumn{2}{|c|}{$3(3)$} & \\
\hline \multirow[t]{2}{*}{ Type D personality, $n(\%)^{\ddagger}$} & No & \multicolumn{2}{|c|}{$84(84)$} & \multicolumn{2}{|c|}{$67(67)$} & 0.028 \\
\hline & Yes & \multicolumn{2}{|c|}{$16(16)$} & \multicolumn{2}{|c|}{$33(33)$} & \\
\hline
\end{tabular}

$S D$ - standard deviation. ${ }^{*}$ Mann-Whitney $U$ test, ${ }^{+}$Student's $t$ test, ${ }^{*} \chi^{2}$ test

of the disease and SF-36 domains. A $p$ value $<0.05$ was considered significant.

\section{Results}

There were no statistically significant differences in the demographic characteristics between the 100 patients with anal fissure and the 100 healthy volunteers (Table I). Negative affectivity sub-scale scores were found to be higher in patients with anal fissure than in controls $(p<0.05)$. Also, patients with anal fissure scored lower on physical roles and bodily pain dimensions of SF-36 than healthy subjects. Thirty-three patients with anal fissure (33\%) and 16 controls (16\%) scored above the cut-off score of the DS14 $(p<0.05)$.

As can be seen in Table II, NA was significantly related to social roles and mental health. Social inhibition was found to be significantly associated only with bodily pain.

Patients were evaluated according to whether they had acute or chronic disease. Seventy-nine patients
Table II. Correlations among negative affectivity, social inhibition and SF-36 dimensions in patients with anal fissure

\begin{tabular}{lcc}
\hline Parameter & NA & SI \\
\hline Age & -0.020 & 0.003 \\
\hline Duration of the disease [weeks] & -0.129 & 0.137 \\
\hline Physical function & -0.163 & -0.130 \\
\hline Physical roles & -0.041 & -0.091 \\
\hline Bodily pain & -0.191 & $-0.307^{* *}$ \\
\hline General health & -0.013 & -0.074 \\
\hline Vitality & 0.085 & -0.162 \\
\hline Social roles & $-0.215^{*}$ & -0.130 \\
\hline Emotional roles & -0.057 & 0.092 \\
\hline Mental health & $-0.218^{*}$ & -0.139
\end{tabular}

$N A-$ negative affectivity, $\mathrm{SI}-$ social inhibition. ${ }^{*} p<0.05,{ }^{* *} p<0.01$

(79\%) had acute and 21 patients (21\%) had chronic anal fissure. We did not find statistically significant differences between the patients with acute and chronic anal 
Table III. Comparison of patients with anal fissure according to the chronicity of anal fissure

\begin{tabular}{|c|c|c|c|c|c|c|}
\hline \multirow[t]{2}{*}{ Parameter } & & \multicolumn{2}{|c|}{ Acute $(n=79)$} & \multicolumn{2}{|c|}{ Chronic $(n=21)$} & \multirow{2}{*}{$\begin{array}{l}\text { Value } \\
\text { of } p\end{array}$} \\
\hline & & Mean & SD & Mean & SD & \\
\hline Age $^{*}$ & & 33.6 & 12.0 & 36.4 & 9.0 & 0.118 \\
\hline Duration of the disease [weeks] ${ }^{\star}$ & & 2.8 & 1.2 & 16.3 & 13.7 & $<0.001$ \\
\hline Negative affectivity* & & 9.7 & 4.0 & 9.0 & 3.8 & 0.691 \\
\hline Social inhibition* & & 9.2 & 3.5 & 8.9 & 5.5 & 0.613 \\
\hline Physical function* & & 77.2 & 18.5 & 78.8 & 18.6 & 0.692 \\
\hline Physical roles* & & 76.4 & 15.9 & 80.4 & 16.6 & 0.281 \\
\hline Bodily pain* & & 73.9 & 20.5 & 73.4 & 21.7 & 0.955 \\
\hline General health* & & 75.9 & 13.4 & 77.2 & 15.8 & 0.381 \\
\hline Vitality* & & 80.3 & 14.1 & 77.4 & 15.4 & 0.440 \\
\hline Social roles* & & 79.2 & 17.0 & 81.9 & 17.1 & 0.412 \\
\hline Emotional roles* & & 79.1 & 16.3 & 80.0 & 16.4 & 0.717 \\
\hline Mental health* & & 83.8 & 10.2 & 84.4 & 9.3 & 0.827 \\
\hline \multirow[t]{2}{*}{ Gender, $n(\%)^{\dagger}$} & Male & \multicolumn{2}{|c|}{$41(51.9)$} & \multicolumn{2}{|c|}{$7(33.3)$} & 0.130 \\
\hline & Female & \multicolumn{2}{|c|}{$38(48.1)$} & \multicolumn{2}{|c|}{$14(66.6)$} & \\
\hline \multirow[t]{2}{*}{ Type D personality, $n(\%)^{\dagger}$} & No & \multicolumn{2}{|c|}{$53(67.1)$} & \multicolumn{2}{|c|}{$17(66.6)$} & 0.971 \\
\hline & Yes & \multicolumn{2}{|c|}{$26(32.9)$} & \multicolumn{2}{|c|}{$7(33.3)$} & \\
\hline
\end{tabular}

$S D$ - standard deviation. ${ }^{*}$ Mann-Whitney $U$ test, ${ }^{+} \chi^{2}$ test

Table IV. Comparison of patients with anal fissure according to the presence of a type D personality

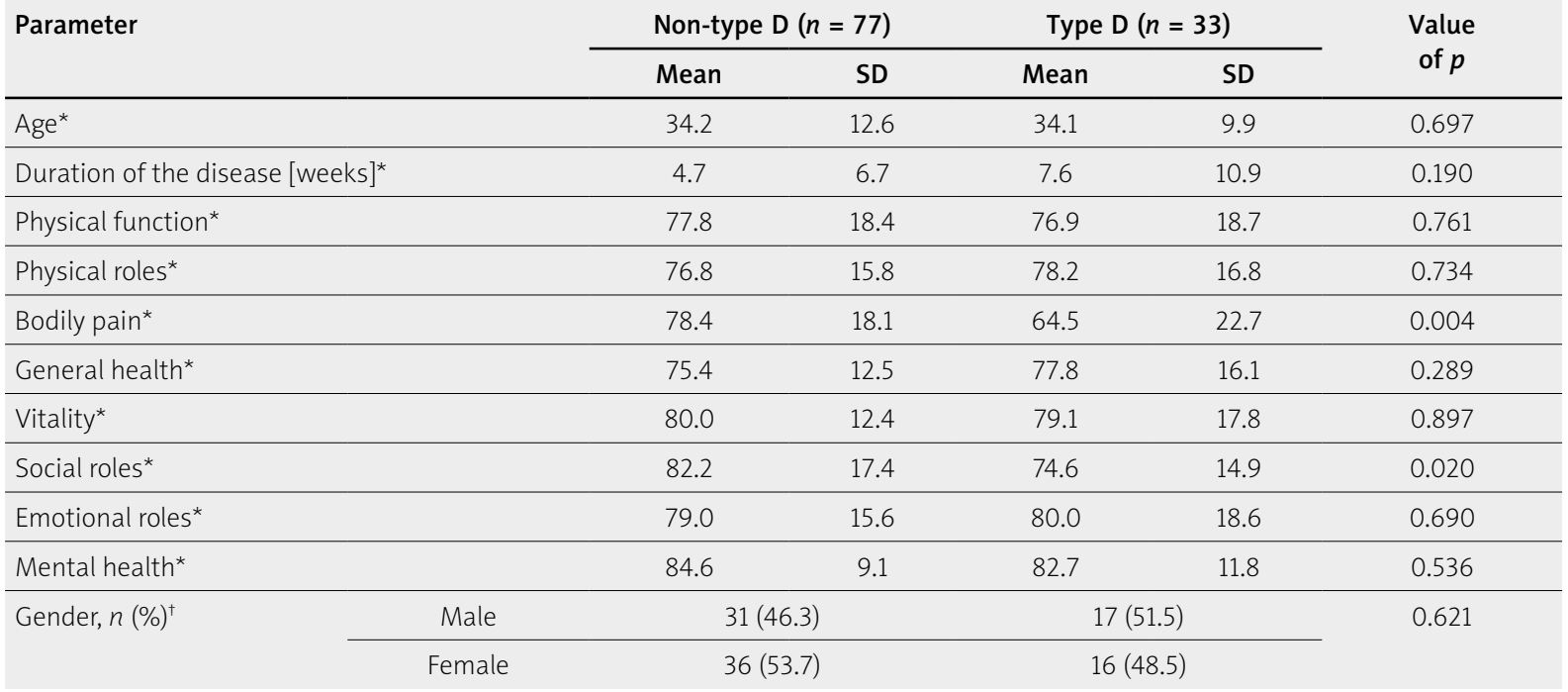

$S D$ - standard deviation. *Mann-Whitney $U$ test, ${ }^{+} \chi^{2}$ test

fissure with respect to demographic characteristics, $\mathrm{NA}, \mathrm{SI}$ and health-related quality of life dimensions (Table III). The duration of the disease was longer in patients with chronic anal fissure, as expected ( $p<0.001$ ).

Patients with anal fissure were divided into two groups according to the presence of a type $D$ personality (Table IV). Patients with a type D personality were found to score lower on bodily pain $(p<0.01)$ and social roles $(p<0.05)$ dimensions of SF-36 than patients without a type $D$ personality.

\section{Discussion}

In this study, we investigated the prevalence and the effect on HRQL of type D personality in patients with anal fissure. Patients with anal fissure were found to score lower on physical roles and bodily pain dimen- 
sions of SF-36 than healthy subjects. One-third of the patients were found to have a type $D$ personality; this prevalence was significantly higher than that (16\%) found in healthy controls. Moreover, bodily pain and social roles dimension of the HRQL were significantly different (i.e. worse) in patients with a type $D$ personality when compared to patients without a type $D$ personality.

At the time of writing, only two studies were conducted regarding HRQL in patients with anal fissure. In the first study, Griffin et al. [10] showed improvement in bodily pain, role-physical functioning and vitality dimensions of SF-36 after an 8-week course of topical treatment. In the second study, Ortiz et al. [9] evaluated the effect of lateral internal sphincterotomy on HRQL in 108 patients with chronic anal fissure, and showed improvement inphysical functioning, physical roles, bodily pain, vitality, social functioning and mental health dimensions. Menteş et al. [8] also investigated the impact of treatment (lateral internal sphincterotomy) on quality of life, using the Gastrointestinal Quality of Life Index questionnaire, and found that quality of life improved significantly following lateral internal sphincterotomy, regardless of the surgical complications or postoperative disturbances of continence. Although these studies have shown an improvement in quality of life after treatment, none of them have compared the HRQL of patients with that of individuals without anal fissure. Moreover, these studies have not included patients with acute anal fissure, which may lead to underestimating the effect of symptomatic anal fissure on HRQL. In the present study, we enrolled symptomatic patients with acute and chronic anal fissure, as well as healthy individuals as controls. There were no differences between the patients with acute and chronic anal fissure with respect to NA, SI and HRLQ dimensions, indicating that personality traits and quality of life were not associated with the duration of anal fissure. We found that patients with anal fissure had increased bodily pain and impaired physical roles when compared with healthy controls. Thus, symptomatic anal fissure was shown to influence HRQL negatively.

Type D personality is found in around one-sixth of the general population [14], and the prevalence of type $D$ personality in cardiac patients varies widely from $5.3 \%$ to $53 \%$ [2]. In the present study, a similar prevalence (33\%) of type D personality was found among patients with anal fissure. The current study has shown that type $D$ personality construct is fairly prevalent among patients with anal fissure.

The present study needs to be evaluated in light of several limitations. First, the study sample was relatively too small to draw definite conclusions. Second, other personality traits such as neuroticism, extroversion, openness, conscientiousness and agreeableness were not evaluated. Third, psychological distress was not assessed in this study because our aim was to evaluate personality traits that have been shown to be stable over time. Additional studies are needed to evaluate the interactions among type D personality structure, symptom severity, HRQL and psychological states.

\section{Conclusions}

To the best of our knowledge, this study is the first to investigate the effect of type D personality on HRQL in patients with anal fissure. Type $D$ patients were more likely to have worse social roles and bodily pain when compared with non-type D subjects. Moreover, NA was significantly related to social roles and mental health, and SI was found to be significantly associated with bodily pain. To conclude, personality in general, and type $\mathrm{D}$ personality in particular, may be an important determinant of individual differences in $\mathrm{HRQL}$ in anal fissure. Type D personality should be an important consideration in the management of patients with anal fissure. A multidisciplinary treatment team, involving psychologists, rehabilitation counsellors or specialist nurses might be required, since assessment and treatment efforts are comprehensive in these patients. Consideration of personality traits may allow for improved risk stratification in research and clinical practice in this patient group. Further studies are needed to evaluate whether or not patients with anal fissure exhibiting type $D$ personality trait show greater dissatisfaction with medical interventions, are less compliant with medical therapyor have inferior therapeutic outcomes.

\section{Acknowledgments}

The named authors consent to publication and meet the requirements of authorship as set out by the journal.

\section{References}

1. Lund JN, Scholefield JH. Aetiology and treatment of anal fissure. Br J Surg 1996; 83: 1335-44.

2. Denollet J. DS14: standard assessment of negative affectivity, social inhibition, and type D personality. Psychosom Med 2005; 67: 89-97.

3. Williams L, O'Connor RC, Howard S, et al. Type-D personality mechanisms of effect: the role of health-related behavior and social support. J Psychosom Res 2008; 64: 63-9.

4. Schiffer AA, Denollet J, Widdershoven JW, et al. Failure to consult for symptoms of heart failure in patients with a type-D personality. Heart 2007; 93: 814-8.

5. Grande G, Romppel M, Barth J. Association between type D personality and prognosis in patients with cardiovascular diseases: a systematic review and meta-analysis. Ann Behav Med 2012; 43: 299-310. 
6. Mols F, Denollet J. Type D personality among noncardiovascular patient populations: a systematic review. Gen Hosp Psychiatry 2010; 32: 66-72.

7. Glise $\mathrm{H}$, Wiklund I. Health-related quality of life and gastrointestinal disease. J Gastroenterol Hepatol 2002; 17 Suppl.: S72-84.

8. Menteş BB, Tezcaner T, Yilmaz U, et al. Results of lateral internal sphincterotomy for chronic anal fissure with particular reference to quality of life. Dis Colon Rectum 2006; 49: 1045-51.

9. Ortiz H, Marzo J, Armendariz P, et al. Quality of life assessment in patients with chronic anal fissure after lateral internal sphincterotomy. Br J Surg 2005; 92: 881-5.

10. Griffin N, Acheson AG, Tung P, et al. Quality of life in patients with chronic anal fissure. Colorectal Dis 2004; 6: 39-44.

11. Alçelik A, Yıldırım O, Canan F, et al. A Preliminary psychometric evaluation of the type $D$ personality construct in Turkish hemodialysis patients. JMOOD 2012; 2: 1-5.

12. Ware JE, Sherbourne CD. The MOS 36-Item Short-Form Health Survey (SF-36). I. Conceptual framework and item selection. Med Care 1992; 30: 473-83.

13. Koçyiğit H, Aydemir Ö, Fişek G, et al. Kısa Form-36 (KF-36)'nın Türkçe versiyonu'nun güvenilirliği ve geçerliliği [Turkish]. İlaç ve Tedavi Dergisi 1999; 12: 102-6.

14. van Bon-Martens MJ, Denollet J, Kiemeney LA, et al. Health inequalities in the Netherlands: a cross-sectional study of the role of type D (distressed) personality. BMC Public Health 2012; 12: 46.

Received: 14.06 .2013

Accepted: 8.08.2013 